\section{B A Institute of \\ YK Business Administration \\ 六下 \\ Karachi \\ Leadership and Ideas for Tomorrow}

Business Review

Volume 4 Issue 2 July-December 2009

7-1-2009

\title{
The impact of manager's orientation on the job satisfaction of their subordinates
}

\author{
Sarwat Sultan \\ Bahauddin Zakariya University, Multan, Pakistan \\ Afia Hanif \\ Bahauddin Zakariya University, Multan, Pakistan
}

Follow this and additional works at: https://ir.iba.edu.pk/businessreview

Part of the Business and Corporate Communications Commons, Business Intelligence Commons, and the Labor Relations Commons

\section{(c) (1)}

This work is licensed under a Creative Commons Attribution 4.0 International License.

\section{Recommended Citation}

Sultan, S., \& Hanif, A. (2009). The impact of manager's orientation on the job satisfaction of their subordinates. Business Review, 4(2), 87-96. Retrieved from https://doi.org/10.54784/1990-6587.1333

This article is brought to you by iRepository for open access under the Creative Commons Attribution 4.0 License and is available at https://ir.iba.edu.pk/businessreview/vol4/iss2/7. For more information, please contact irepository@iba.edu.pk. 


\title{
DISCUSSION
}

\section{The Impact Of Managers' Orientation On The Job Satisfaction Of Their Subordinates}

\author{
Sarwat Sultan and Afia Hanif \\ Bahauddin Zakariya University, Multan, Pakistan
}

\begin{abstract}
The present research was designed to explore the impact of manager's orientation on the job satisfaction of their subordinates. The sample consisted of 120 employees; 20 managers and 100 of their subordinates ranging in age from 23 to 54 taken from different organizations of Multan. Motivator's Orientation Questionnaire (Deci, Connell, \& Ryan 1989) and Job Satisfaction Questionnaire (Hackman \& Oldham, 1975) were used to collect the information. Results indicated that subordinates working under autonomy oriented managers are more satisfied with their jobs as compared to the subordinates working under controlled oriented managers. Findings pertaining to gender differences suggested that female have more job satisfaction than their male counterparts under autonomous manager.
\end{abstract}

Key Words; Job satisfaction, autonomy orientation, control orientation, extrinsic/intrinsic motivation.

\section{INTRODUCTION}

Human Behaviors vary in the degree to which they are volitional or self-determined. Behaviors can be characterized in terms of the degree to which they are autonomous versus controlled. Self-determination theory (SDT) explains human motivation in terms of development and function of personality in social environment. The theory defines the level to which human behaviors are volitional (an unpressured willingness to engage in an activity) or self-determined - that is, the degree to which people act according to their will and choice (Deci \& Ryan, 2000).

SDT presents the difference autonomous and controlled motivation. Autonomy involves acting with a full sense of volition and endorsement of an action. When autonomously motivated, the perceived locus of causality for action is internal and people experience the behavior as a reflection of who they are. There are two bases for autonomous motivation: intrinsic vs. extrinsic motivation (Deci \& Ryan, 2000). People with intrinsic motivation when involve in an activity, they find it enjoyable and interesting at same level. While with extrinsic motivation people do work for tangible rewards without considering the work itself. According to SDT, the value and regulation of an extrinsically motivated behavior can be internalized to varying degrees, and the more fully it is internalized the more it provides the basis for autonomous extrinsic motivation. 
When the regulation of a behavior has been well internalized, people identify with its personal value for themselves and thus perform the behavior volitionally because of its importance for their own lives and self-selected goals (Deci \& Ryan, 1985b; Ryan \& Deci, 2000).

Behavior is autonomous (or self determined) when our interests, preferences, and wants guides our decision making process to engage or not to engage in a particular activity. We are not self determining (i.e. our behaviors are determined by others) we some outside force pressure us to think, feel, or behave in a particular ways. Formally, autonomy is the need to experience choice, in the initiation and regulation of behavior, and it reflects the desire to have ones choices rather than environmental events to determine one's actions (Deci \& Ryan, 1985a).

Autonomy refers to which a job offers freedom and independence to employee to design their job and tasks, and to determine the way of achieving goals. Autonomy in the organizations increases job satisfaction in employees. Many companies now rely on autonomous structure at work teams. Autonomous culture in the organization offers many advantages employees in form of satisfaction but at the same level it also may have drawbacks (Simmering, 2006).

Environments, external events, social contexts, and relationships all vary in how much versus how little they supports a person's need for autonomy. Some environments involve and nurture our need for autonomy, while others neglect and frustrate this need. For instance, when environment imposes a deadline it interferes with autonomy, but it provides opportunities for self direction, it supports autonomy. Relationships too can sometimes and other times thwart our need for autonomy, as when a manager listens carefully to her employees and uses that information to give employees opportunities to work in their own way and at their own pace (supporting their autonomy). When environments, relationships, social contexts, and cultures successfully involve and satisfy people's need for autonomy, these environments are referred to as autonomy supportive; when environments, relationships, social contexts, and cultures neglect and frustrate, and interfere with people's need for autonomy; these environments are referred to as controlling (Deci \& Ryan, 1987).

Autonomy supportive environments encourage people to set their own goals, direct their own behavior, and choose their own ways of solving problems, and basically pursue their own interests and values. In doing these things, autonomy support catalyzes the person's intrinsic motivation, curiosity and desire for challenge (Deci, Nezlak \& Sheinmen, 1981; Ryan \& Grolnik, 1986). What autonomy supportive environments are not, however, are environments that are not permissive, neglecting, indulging, or laissezfaire (Ryan, 1993). Rather when people work for creating autonomy supportive environments for others (for their children, students, workers, athletes, etc.), they work hard to identify and support the other's interests, needs and strivings.

The opposite of autonomy support environment is a controlling one. Controlling environments essentially ignore people's need for autonomy and instead pressure them to comply with a pre- arranged and externally prescribed way of thinking, feeling or 
behaving. So what gets supported in a controlling environment is not the person's autonomy but an agenda that is external to that person, such as what the teachers want the students to do, what the manager want the workers to do, or what the coaches makes the athletes do while practicing her support. Instead of supporting people's autonomy, controlling controls people's behavior (Reeve, 2005).

Although autonomy create sense of responsibility in employees that may result in higher productivity and job satisfaction, but out of boundaries autonomy may also create dissatisfaction in employees. Actually it has been found that all individuals do not have the same level of need for autonomy in his or her job. Some of the employees like more supervision from a manager and feel uneasy with high autonomy at work; they may not have desire to do with more efforts or may not ready to take the responsibility alone of doing work solely. Furthermore, if employees are with some deficiencies in terms of not well training or personality traits to use autonomy, it may cause distress at work tasks, stress and low activity. Finally, when employees are given autonomy, they experience authority and feel equal to that of their boss that may result in them to create the more sense of responsibility. They may also demand an increase in their salaries. In short, autonomy is often a positive concern for employees and managers. Workers usually demand autonomy that increases job satisfaction. However, the too much autonomy can have organizational drawbacks, and a care is needed when increasing it (Simmering, 2006).

Keeping in view the importance of autonomy vs. controlled orientations, the present study aimed to examine the job satisfaction of employees working under the autonomous vs. control oriented managers. Another objective of this investigation was to see the gender differences in this regard. On the basis of existing literature following hypothesis was formulated.

1. The employees working under the autonomy oriented managers will be more satisfied with their jobs as compared to the employees working under the control oriented managers.

2. Female employees working under the autonomy oriented managers will be more satisfied with their jobs as compared to their male counterparts.

3. Offering the moderate level of autonomy for employees will be more beneficial for organizations than higher level of autonomy.

\section{METHOD}

\section{Participants}

The sample consisted of 120 employees; 20 managers and 100 their subordinates ranging in age from 23 to 54 . All the respondents were taken from the different organizations of Multan. To select the sample, non-probability convenience sampling technique was used. 


\section{Instruments}

Following instruments were used to achieve the objectives of the present study.

\section{Motivator's Orientation Questionnaire; Problems at Work Questionnaire (PAW)}

Problems at Work Questionnaire (Deci, Connel \& Ryan 1989) assesses whether managers tend to be controlling versus autonomy supportive with their employees. PAW was designed to be completed by the managers working in a position of authority and to influence the employee's behavior at work. The measure is composed of eight vignettes, each of which is followed by four items. The four items following each vignette represent four different behavioral options for dealing with the problem that is posed in the vignette: Highly Autonomy Supportive (HA), Moderately Autonomy Supportive (MA), Moderately Controlling (MC), and Highly Controlling (HC). Respondents rate the degree of appropriateness of each of the four options (on a seven-point scale) for each of the eight situations. The procedure for scoring the questionnaire begins by averaging the eight ratings in each of the four categories. The four subscale scores (composed of the average of the eight responses for that subscale) can be combined into one overall reflection of the "Manager's Orientation Toward Control Versus Autonomy Support." The procedure for combining the four subscales into one total scale score involves weighting the average for the highly controlling responses with a -2 (minus two); weighting the moderately controlling average with -1 (minus one); weighting the average for the moderately autonomous subscales with +1 ; and weighting the average for highly autonomous with +2 . The algebraic sum reflects the manager's orientations toward control versus autonomy support, with a higher score reflecting a more autonomy supportive orientation and a lower score or a more negative score reflecting a more controlling orientation The items that make up the subscales are as follows.

$\mathrm{HC} \quad 3,8,9,16,17,22,27,32$

MC $\quad 1,6,12,14,19,24,25,30$

MA $\quad 4,7,10,15,20,21,26,31$

HA $\quad 2,5,11,13,18,23,28,29$

\section{General Job Satisfaction Questionnaire}

General Job Satisfaction Questionnaire (Hackman \& Oldham 1976) was used to assess the job satisfaction of employees. This scale is structured as a 15-item with 5 -point ratings wherein responses ranged from strongly agree to strongly disagree. Two items $12 \& 15$ are reversed scored. In reverse-score an item score of 5 becomes 1,4 becomes 2, 2 becomes 4, 1 becomes 5, and a score of 3 remains unchanged. The maximum score is 75 and the lowest is 15 . Overall internal reliability of scale is 0.77 .

\section{Procedure:}

For the present study, 20 managers and 5 subordinates of each manager $(\mathrm{N}=100)$ were contacted in their organizations at Multan. On the basis of the Problems at Work 
Questionnaire filled out by managers, the managers were categorized as autonomous oriented managers $(\mathrm{N}=13)$ and control oriented managers $(\mathrm{N}=7)$. General Job Satisfaction Questionnaire was distributed to those employees who volunteered to participate in the study. Employees working under autonomous oriented managers $(\mathrm{N}=65)$ and employees working under control oriented managers $(\mathrm{N}=35)$ filled out General Job Satisfaction Questionnaire. Respondents were assured of the complete confidentiality of their responses and the importance of accurate responses was emphasized. Results were analyzed by using SPSS (Statistical Package for Social Sciences).

\section{RESULTS}

Mean, SD, and independent sample t-test were computed in order to test the hypotheses in the present study.

\section{Table 1}

Difference in the level of job satisfaction of employees working under autonomy oriented managers $(N=65)$ and control oriented managers $(N=35)$

\begin{tabular}{llll}
\hline Employees & M & SD & t \\
Working under Autonomy Oriented Managers & 259.54 & 17.85 & $16.11^{* *}$ \\
$\begin{array}{l}\text { Working under Control oriented Managers } \\
d f=98, * *<0.01\end{array}$ & 207.43 & 13.95 & \\
\hline
\end{tabular}

Table 2

Difference in the level of job satisfaction of males $(N=58)$ and females $(N=7)$ working under autonomy oriented managers

\begin{tabular}{llll} 
Gender & M & SD & t \\
\hline Male & 257.76 & 17.92 & $4.36^{* *}$ \\
Female & 274.29 & 7.87 & \\
$d f=63, * * * p<0.01$ & & & \\
\hline
\end{tabular}

Table 3

Difference in the level of job satisfaction of employees working under high autonomy oriented managers $(N=23)$ and moderate autonomy oriented managers $(N=42)$.

\begin{tabular}{|c|c|c|c|}
\hline Employees & M & SD & $\mathbf{t}$ \\
\hline $\begin{array}{l}\text { Working under High Autonomy Oriented Managers } \\
\text { Working under Moderate }\end{array}$ & 113.54 & 08.15 & $13.43 *$ \\
\hline $\begin{array}{l}\text { Autonomy oriented Managers } \\
d f=63, * * p<0.05\end{array}$ & 137.14 & 10.93 & \\
\hline
\end{tabular}


Results depicted in Table 1, 2, and 3 show the significant difference in level of job satisfaction of employees. Findings (Table 1) suggest that subordinates working under the autonomy oriented managers are more satisfied $(t=16.11, p<0.01)$ with their jobs than the subordinates of controlled managers. Results depicted in Table 2 indicate that females have greater level of job satisfaction $(t=4.36, p<0.01)$ under the supervision of autonomous motivator as compared to males. Table 3 reveals that employees of managers having moderate autonomy supportive have greater level of job satisfaction $(t=13.43, p<0.01)$ as compared to the employees under the supervision of highly autonomous motivators.

\section{DISCUSSION}

Environment in any organization where the employees work together definitely affect the productivity level and satisfaction with jobs of the employees. Many factors are involved in maintaining healthy environment for organizations. One of the most important factors is related to the managers' characteristics i.e. gender, age, education, training, personality, and particularly the way of supervision. As discussed earlier, managers' orientations can be of two types; autonomy vs. control. For instance, the present study focused on knowing how differences in the orientations for supervision of managers affect the employees' level of satisfaction with their jobs. The data was analyzed on the basis of the assumption that there would be difference in level of job satisfaction of subordinates working under the managers with different orientations. Men and women working under autonomous vs. control orientations will also have different attitude towards their jobs, was another objective of the study.

The first hypothesis of the study which states that the employees working under autonomy oriented managers will be more satisfied with their jobs as compared to the employees working under the control oriented managers, has been supported in the study. The results showed that the subordinates working under the autonomy oriented managers have greater level of job satisfaction; while subordinates of control oriented managers have low level of job satisfaction. These finding are in tune with the previous study conducted by Deci, Connell \& Ryan (1989) who reported that manager whose orientation for supervision is supportive and autonomous affects the perceptions, attitudes, motivation, and satisfaction of subordinates. Subordinates who worked under autonomous managers will have the work atmosphere that give them the chance to contribute their decision making process of organizations. Such an atmosphere helped to create in them a sense of psychological freedom and as a result of this psychological freedom they took interest in their job and used to be committed and satisfied with their jobs and organization as well. Research appears to be equivocal since most research indicates that individuals are likely to have high levels of job satisfaction if supervisors provide them with support and co-operation in completing their tasks (Ting, 1997).

There can be several plausible reasons for these findings because theory of management explains that subordinates who work under the supervision of seniors having autonomous approach, may be task oriented, having a strong desire for success or achievement, motivated to work, and ready to accept greater responsibility. They 
may also have control on their self, direction for self, independence, and empowerment under the autonomous supervision. It is a fact that employees feel good and pleasure when their mental and physical work duties do. And it is believed that if employees are given the chance they wish to do more creativity in tasks assigned to them. They come to the advance solutions for predicaments through their forward thinking in the organizations. Freedom for doings at workplace may result in greater productivity and especially when independency is more offered to employees to perform job at the best of their skills and competencies without being slow down by authorities. So managers with this orientation make their employees free and create in them a sense of psychological freedom, which results in greater satisfaction of employees. The above findings are corroborated by Staudt's (1997) research based on social workers in whom it was found that respondents, who reported satisfaction with supervision, were also more likely to be satisfied with their jobs in general.

On the other hand control oriented managers bound their subordinates to work according to their values and rules. In fact a manager of control orientation assumes that his or her subordinates do not want to work hard in actual, that they would not pay attention to solve problems, that they do not take responsibility, and that it is only the manager's responsibility to look upon issues, to manage work, to design the job, to keep spirit high for work, and to motivate the employees. These assumptions of control oriented manager bring authoritarian management style that is generally focused on the threats of punishment. One major flaw of this type of orientation is it is much to cause the employees least interest in the job and commitment to the organization. These findings are in favor of the findings of the work of Billingsley and Cross (1992) as well as Cramer (1993). These researchers generally hold that dissatisfaction with management supervision is a significant predictor of job dissatisfaction. These differences between autonomy and control oriented managers are also significant as to convince the reader of the credibility of the finding of present study.

As far as the second hypothesis is concerned, the findings are statistically significant. It was assumed that females working under the autonomous manager will be more satisfied to their jobs as compared to their male counterparts (Table 2). These findings are in line with the previous study conducted by Jinnett \& Alexander (1999). According to this study, female employees demonstrate higher levels of job satisfaction than their male counterparts across most work settings. Because of the friendly and free environment provided by autonomous managers, female employees felt more satisfaction with their jobs. They feel comfortable and convenient in such environment where they are asked about the organizational decisions. Because females used to live in the authoritative and controlled environment at their homes, so when are in work settings they have the autonomous environments they tend to show higher satisfaction and commitment as compared to their male counterparts. One of the most popular explanations is that men and women attach value to different aspects of the job. In addition to placing greater emphasis on co-worker relations, women are also more inclined to assign priority to work that provides them with a sense of accomplishment (Tolbert \& Moen, 1998). Furthermore, women may compare themselves only with other women or with women who stay at home rather than with all other employees (Hull, 1999). Instead of having 
low positions woman in our culture tend to be satisfied and committed to their jobs as compared to their male counterparts. Because rather than comparing themselves with their colleagues they used to compare themselves with those females not having the chance to come out of their homes. Their sphere of activities is only their home, children and spouses. And have no chance to for progress. So the working women tend to be thankful to their God and their spouses or parents for providing them with the chance of progressing in the outer world. So this sense of self-fulfillment enhances their involvement in their jobs and they tend to be more satisfied and committed to their jobs.

Results pertaining to the third hypothesis which states that employees working under moderate autonomy oriented managers will be more satisfied their jobs as compared to the employees working under high autonomy oriented managers have also been supported in the present study (Table 3). Researches indicated that the quality and quantity of the supervisor-subordinate relationship would have a significant, positive influence on the employee's overall level of job satisfaction (Aamodt, 1999; Kinicki \& Vecchio, 1994). Chieffo (1991) maintains that supervisors who allow their employees to participate in decisions that affect their own jobs will, in doing so, stimulate higher levels of employee satisfaction.

This also may coincide with the work of Simmering, (2006) who reported that structure and culture of any organization generally determine the autonomy of employees and managers. Bureaucratic organizations generally restrict the autonomy, and do not offer autonomous environment in organizations for their employees. These types of organizations newer rely on autonomy, motivation to succeed, and empowering employees that may result in dissatisfaction in employees. While the organizations that offer autonomy for their employees, get the benefits of higher productivity, job satisfaction, and job commitment. Autonomy reduces some of the relational barriers between managers and subordinates. Therefore, through involvement, suggestions, and participation of employees in organizational decisions, workplace functions can be facilitated. Autonomy generates higher level of trust in relationships between managers and employees. But it is important to keep in knowledge that too much autonomy or free hand in the organization also may create inequality and difference in many respects. In the worst situation, employees may demonstrate unwanted and unethical behaviors if they get high freedom and autonomy, and do not have any check by authorities. Thus, it is suggested that a certain amount of check is needed in organizations to minimize wrongdoing that may go unnoticed when there are high levels of autonomy (Simmering, 2006).

\section{CONCLUSION}

On the basis of the findings obtained in the present study it is concluded that:

1. Employees working under the autonomy oriented managers have more job satisfaction as compared to the employees working under the control oriented managers.

2. Females working under the autonomy oriented managers are more satisfied with their jobs as compared to their male counterparts. 
3. Employees working under moderate autonomous environment, are more satisfied with their jobs than the employees working under high autonomy supportive environment

\section{Limitations and Suggestions}

This investigation bore some limitations in that it relied on a convenience sample taken from the different organizations in Multan, and the sample used in the present research is not large enough to represent the whole population, the findings therefore can not be generalized specially to the other sample that can have totally different social background. The study may well be replicated in other settings, exploring some more variables which could be associated with job satisfaction e.g. education level, age, rural vs urban, and socio economic class.

\section{REFERENCES}

Aamodt, M.G. (1999). Applied Industrial/Organizational Psychology (3rd ed). Belmont: Wadsworth Publishing Company.

Billingsley, B.S., and Cross, L.H. (1992). Predictors of commitment, job satisfaction, and intent to stay in teaching: A comparison of general and special educators. Journal of Special Education, 25(4), pp 453-472.

Chieffo, A.M. (1991). Factors contributing to job satisfaction and organizational commitment of community college leadership teams. Community College Review, 19(2), pp 15-25.

Cramer, D. (1993). Tenure, commitment, and satisfaction of college graduates in an engineering firm. Journal of Social Psychology, 133(6), pp 791-797.

Deci, E. L., Connell, J. P., \& Ryan, R. M. (1989) Self-determination in a work organization, Journal of Applied Psychology, 74, pp 580-590.

Deci, E.L., Nezlak, J., \& Sheinman, 1. (1981). Characteristics of rewarder and intrinsic motivation of the rewardee. Journal of personality and social psychology, 40, pp 1-10.

Deci, E.L., \& Ryan, R. M. (1985a). Intrinsic motivation and self-determination in human behavior. New Yoprk: Pnelum.

Deci, E.L., \& Ryan, R. M. (1985b). The general causality orientation Scale: Self determination in personality. Journal of Research in Personality, 19, pp 109-134.

Deci, E.L., \& Ryan, R. M. (1987). The support of autonomy and the control of behavior. Journal of Personality and Social Psychology, 53, pp 1024-1037.

Deci, E. L., \& Ryan, R. M. (2000). The 'what' and 'why' of goal pursuits: Human needs 
and the self-determination of behavior. Psychological Inquiry, 11, pp 227-268.

Hackman, J.R. \& Oldham, G.R. 1976. Motivation Through the Design of Work: Test of Theory. Organizational Behavior and Human Performance.

Hull, K.E. (1999). The paradox of the contented female lawyer. Law and Society Review, 33(3) pp 687-703.

Jinnett, K., \& Alexander, J.A. (1999). The influence of organizational context on quitting intention. Research on Aging, 21(2): 176-205. Retrieved Feb 15, 2008, from. Kinicki, A.J. \& Vecchio, R.P. (1994). Influences on the quality of supervisor subordinate relations: The role of time-pressure, organizational commitment, and locus of control. Journal of Organizational Behavior, 15(1) pp 75-82.

Reeve J. R. (2005). Autonomy. Understanding Motivation and Emotion., Jhon Willey \& Sons, Inc., III River Street, ISBN 0-471-45619-5.

Ryan, R. M. (1993). Agency and organization: intrinsic motivation, autonomy, and the self in the psychological development. In J. E. Jacobs (Ed). Nebraska symposium on motivation: Developmental perspectives on motivation (Vol. 40,pp 1-56).Lincoln: university of Nebrasks Press.

Ryan, R. M., \& Deci, E. L. (2000). Self-determination theory and the facilitation of intrinsic motivation, social development and well-being. American Psychologist, 55, pp 68-78.

Ryan, R. M., \& Grolnick, W.S. (1986). Origins and pawns in the classroom: Self report and projective assessment of individual differences in children's perceptions. Journal of Personality and Social Psychology, 50, pp 550-558.

Simmering, M.J. (2006). Autonomy. Encyclopedia of Management. Feb 4, 2008. Staudt, M. (1997). Correlates of job satisfaction in school social work. Social Work in Education, 19(1) pp 43-52. Nov 19, 2007.

Ting, Y. (1997). Determinants of job satisfaction of federal government employees, Public Personnel Management, 26(3), pp 313-335.

Tolbert, P.S., \& Moen, P. (1998). Men's and women's definitions of “good” jobs. Work and Occupations, 25(2), pp 168-195. 